\title{
ANL/MSD/PP. 84553
}

\section{A New MBE CdTePhotoconductor Array Detector for X-Ray Applications}

S. S. Yoo ${ }^{1}$, B. Rodricks ${ }^{2}$, J. Bai ${ }^{3,4}$, S. Sivananthan ${ }^{1}$, J. P. Faurie ${ }^{1}$, and P. A. Montano ${ }^{1,3}$

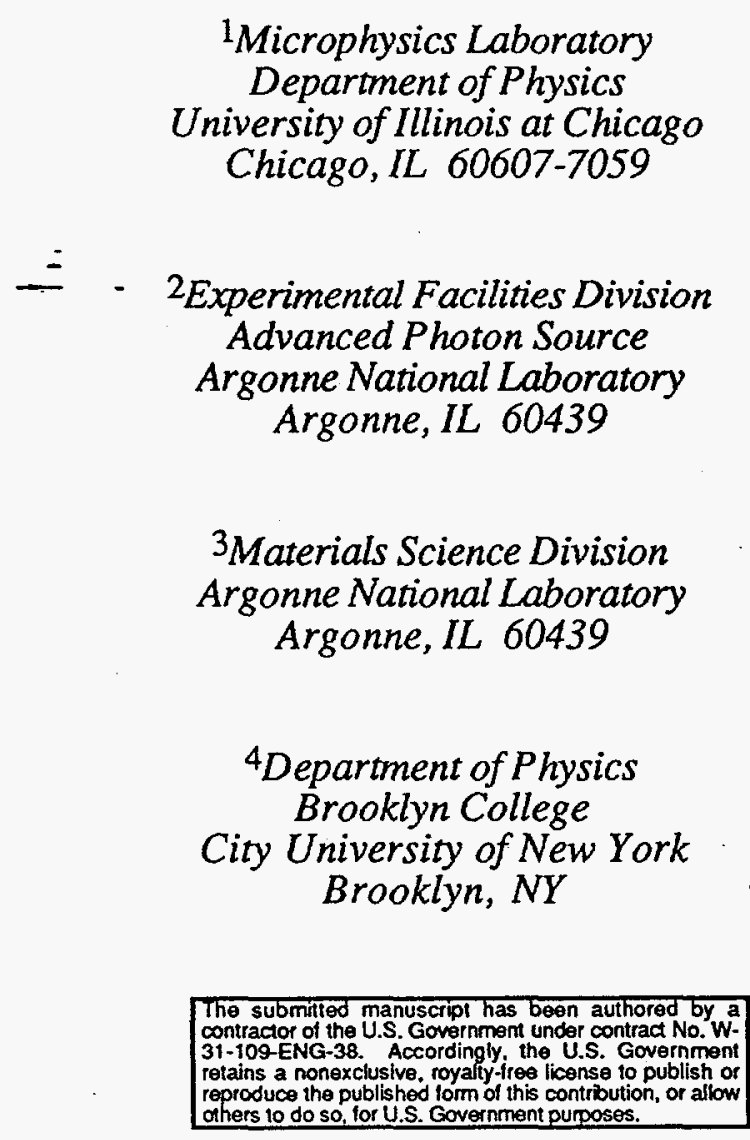

October, 1994

$/ \mathrm{sm}$

Distribution:

1-2. M. J. Masek

3. B. D. Dunlap

4. P. A. Montano

5. F. Y. Fradin

6. Editorial Office

7. Authors

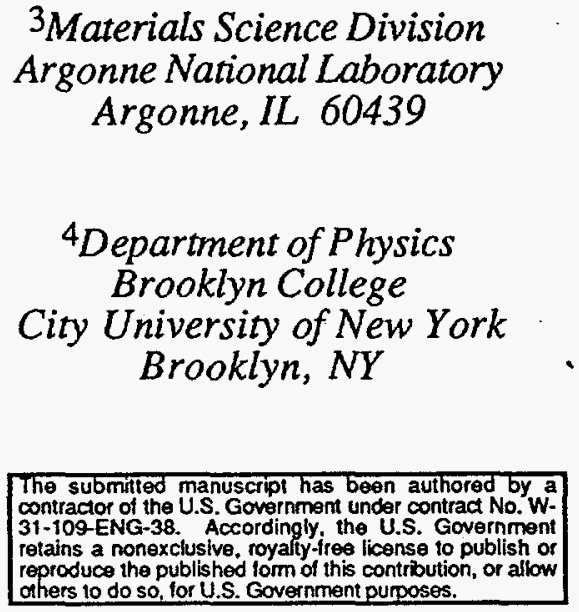

HEIVES

DEC 061996

OSTI 


\section{DISCLADMER}

Portions of this document may be illegible in electronic image products. Images are produced from the best available original document. 


\section{A New MBE CdTePhotoconductor Array Detector for X-Ray Applications}

S. S. Yoo ${ }^{1}$, B. Rodricks ${ }^{2}$, J. Bai' ${ }^{3,4}$, S. Sivananthan ${ }^{1}$, J. P. Faurie1, and P. A. Montano ${ }^{1,3}$

${ }^{1}$ Microphysics Laboratory

Department of Physics

University of Illinois at Chicago

Chicago, IL 60607-7059

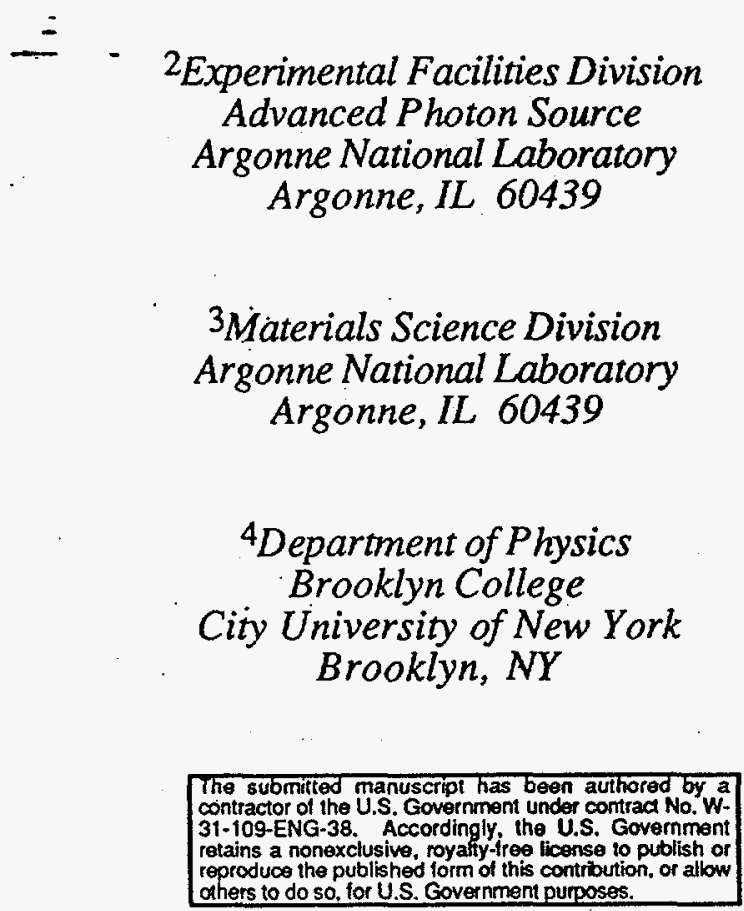

October, 1994

\section{DISCLAIMER}

This report was prepared as an account of work sponsored by an agency of the United States Government. Neither the United States Government nor any agency thereof, nor any of their employees, makes any warranty, express or implied, or assumes any legal liability or responsibility for the accuracy, completeness, or usefulness of any information, apparatus, product, or process disclosed, or represents that its use would not infringe privately owned rights. Reference herein to any specific commercial product, process, or service by trade name, trademark, manufacturer, or otherwise does not necessarily constitute or imply its endorsement, recommendation, or favoring by the United States Government or any agency thereof. The views and opinions of authors expressed herein do not necessarily state or reflect those of the United States Government or any agency thereof.

This work is supported by the Division of Materials Sciences, Office of Basic Energy Sciences of DOE, under contract No. W-31-109-ENG-38. 


\title{
A New MBE CdTe Photoconductor Array Detector For X-Ray Applications
}

\author{
S. S. Yoo ${ }^{1}$, B. Rodricks ${ }^{2}$, J. Bai ${ }^{3,4}$, S. Sivananthan ${ }^{1}$, J. P. Faurie ${ }^{1}$, and P. A. Montano ${ }^{1,3}$
}

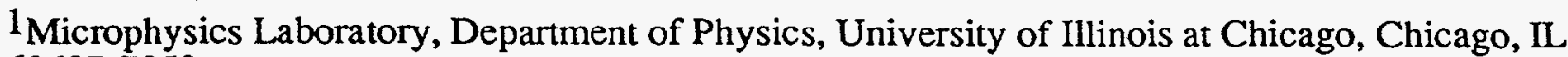
60607-7059

2 Experimental Facilities Division,Advanced Photon Source, Argonne National Laboratory, Argonne, IL 60439

${ }^{3}$ Material Science Division, Argonne National Laboratory, Argonne, IL 60439

4 Department of Physics, Brooklyn College, City University of New York, Brooklyn, NY

\section{ABSTRACT}

A CdTe photoconductor arrày $x$-ray detector was grown using Molecular Beam Epitaxially (MBE) on a Si (100) substrate. The temporal response of the photoconductor arrays is as fast as 21 psec risetime and 38 psec Full Width Half Maximum (FWHM). Spatial and energy responses were obtained using $\mathrm{x}$-rays from a rotating anode and synchrotron radiation source. The spatial resolution of the photoconductor was good enough to provide $75 \mu \mathrm{m}$ FWHM using a $50 \mu \mathrm{m}$ synchrotron $\mathrm{x}$-ray beam. A substantial number of $\mathrm{x}$-ray photons are absorbed effectively within the MBE CdTe layer as observed from the linear response up to $15 \mathrm{keV}$. These results demonstrate that MBE grown CdTe is a suitable choice of the detector materials to meet the requirements for $\mathrm{x}$-ray detectors in particular for the new high brightness synchrotron sources.

The arrival of very bright photon sources like the Advanced Photon Source at ANL will present enormous technological challenges in order to fully utilize its brightness. New fast detectors are necessary for many experimental applications using such a new source. For example, the APS will operate with 25 bunches of $x$-ray pulses with a 72 psec pulse width and a 184 psec period. In order to fully utilize the time resolution and to diagnose the x-ray pulses from the storage ring, it is necessary to develop high speed detectors with good spatial and energy responses. Several kinds of solid state detectors are commercially available for $\mathbf{x}$-ray detection applications. Si detectors are based on the most advanced technologies and their use is very common. However the attenuation coefficient of $\mathrm{Si}$ is so low that the absorption thickness of the detector should be fairly thick in order to stop high energy photons. As a result, the response is slow and limited to the nsec range $(1,2)$. Ge has relatively large atomic number and seems to be a good choice. Since the intrinsic carrier density is large at room temperature, the detector has to be operated at cryogenic temperatures in order to increase the signal-to-noise ratio, thus the system becomes bulky. $\mathrm{Hg}_{2} \mathrm{I}$ is efficient to absorb $\mathrm{x}$-ray photons of high energy. However the carrier mobility is unacceptable to achieve fast response and limits its application to slow processes.

CdTe is a II-VI semiconductor material and was found to be useful for the detection of high energy radiations, such as $\mathrm{x}$ rays and gamma rays $(3,4,5,6)$. The high atomic number of $\mathrm{Cd}(48)$ and $\mathrm{Te}(52)$ and its high stopping power are the main advantage for such radiation detector applications. The bandgap of CdTe is large and the intrinsic carrier concentration is low. The 
resistivity is high enough to operate the devices at room temperature. Because of its large absorption coefficient, $10-20 \mu \mathrm{m}$ thick CdTe layer should be enough to capture most $\mathrm{x}$-ray photons in the interesting energy range for crystallography $(8-20 \mathrm{KeV})$. E. Rossa et al and other groups $(7,8,9)$ attempted to use thin polycrystalline CdTe grown by MOCVD for the detection of ultrashort optical and $\mathbf{x}$-ray pulses. However the use of polycrystalline crystals limits their application because of the large photoconductor dark current. We have utilized MBE grown single crystalline CdTe layers to develop linear photoconductor arrays for synchrotron radiation detection and diagnosis $(10,11,12)$. It is advantageous to use thin MBE grown layers in order to reduce the dark current, besides the benefit of using high density material, CdTe, thus accomplishing a high signal-to-noise ratio at foom temperature. It was reported recently the growth of high crystalline quality MBE (111)B CdTe on (100) Si substrates. Darwin's width of 140 arcs has been obtained on the MBE CdTe layers(13). MBE growth provides a large area uniformity, of both thickness and defect levels $(14)$, which are the basic requirements to obtain uniform response of array devices as in most optical detectors. These high quality materials are readily suitable for $\mathrm{x}$-rays or high energy radiation detector applications and we are of the opinion that MBE CdTe is an ideal choice to achieve array detectors of uniform quality and high performance.

The (111)B CdTe was grown on the (100) orientation of a Si substrate by Molecular Beam Epitaxy at the University of Illinois at Chicago. The details of the growth parameters and conditions are reported elsewhere $(13,14)$. The thickness of the routinely grown CdTe layers varies from $10 \mu \mathrm{m}$ to $20 \mu \mathrm{m}$. The resistivity of the underlying Si substrate is several orders lower than that of MBE grown CdTe. Therefore the CdTe layers were peeled up from the Si substrates and glued on insulating glass. In order to remove the Si substrates without chemically damaging $\mathrm{CdTe}$, An anisotropic etchant of $80 \% \mathrm{KOH}$ was chosen for etching of Si. The chemical etching is enhanced along $\left\langle 011>\right.$ directions of $\mathrm{Si}$, which is along the interface with $\mathrm{CdTe}$. At $120^{\circ} \mathrm{C}$, the $\mathrm{Si}$ substrates are removed from the CdTe glued on the glass within 5 minutes. The surface of the resulting CdTe layer is the interface region with $\mathrm{Si}$ substrate, where high density defects due to lattice mismatch of $\mathrm{Si}(19 \%)$ are expected, therefore the top 1 or $2 \mu \mathrm{m}$ layer was etched in $\mathrm{Br}_{2} / \mathrm{HBr}$. Conventional photolithography was carried out to define linear photoconductor arrays.

The photoconductor gap size varies from $5 \mu \mathrm{m}$ to $50 \mu \mathrm{m}$ with $50 \mu \mathrm{m}$ width. The pitch size is 100 $\mu \mathrm{m}$ and a total 64 photoconductors were fabricated from a $0.8 \times 0.8 \mathrm{~cm}$ size CdTe layer. $10 \mu \mathrm{m}$ wide strips were etched completely between photoconductors in order to prevent crosstalks between the adjacent devices. This procedure was followed by electroless Au deposition or $\mathrm{Au}$ and $\mathrm{Ni}$ sputter deposition for metalization. The array devices were mounted on leadless chip carriers and gold wires were bonded on the bonding pads of each photoconductors.

Current-voltage characteristics were measured under dark conditions, and illumination by an incandescent lamp at room temperature as shown in Fig. 1. The resistivity of the MBE CdTe 
layers is high enough to limit the dark current to less than $\mathrm{InA}$ at $90 \mathrm{~V}$ bias. The measured current in general of such high resistive material is mainly due to the surface leakage current through tunneling at surface states. Taking this into consideration, the resistivity of MBE grown CdTe should be higher than the measured resistance, $2 \times 10^{8} \Omega-\mathrm{cm}$. Under the incandescent light illumination, the current increases by more than two orders of magnitude at $50 \mathrm{~V}$ and slight backto-back diode behavior is observed. The response uniformity was measured on 32 photoconductors. The variations are within $9 \%$ and $5 \%$ for dark and photogenerated currents, respectively. Such small current variation was observed throughout photoconductor arrays on other MBE CdTe layers.

In order to meet the requirements for diagnosis of APS synchrotron $x$-ray pulses, the temporal response should be fast enough to capture the pulses, and the response risetime should be at least in the psec range. $100 \mathrm{fsec}$ Ti:Sapphire laser pulse $(0.745 \mu \mathrm{m})$ was focused on one of the $\mathrm{CdTe}$ photoconductors. For the temporal response measurement, the array device was mounted on a copper block with SMA connectors and high bandwidth coaxial cables. Instead of gold wire used for chip carriers, thin gold foils were used for the connection to a bonding pad of the device. The temporal response of a representative MBE CdTe photoconductor is shown in Fig. 2. The risetime and FWHM of the measured response curve are $20.8 \mathrm{psec}$ and $37.6 \mathrm{psec}$, respectively. It is surprising that such short risetimes are obtained in spite of using single crystal CdTe. In general a fast response is achieved by highly defective or damaged materials, such as polycrystals or ion implanted layers. A. M. Johnson reported $10 \mathrm{psec} F W H M$ from the photoconductor of 0.2 $\mu \mathrm{m}$ thin polycrystalline CdTe grown by UV assisted MOCVD on silica substrates at a low temperature(15). They also achieved various temporal responses by changing deposition parameters or controlling size of grain boundaries. Similarly, subpicosecond response was obtained from thin film (1-2 $\mu \mathrm{m}$ ) MBE grown GaAs photoconductors $(16)$. The GaAs was grown at low temperature so that a great number of point defects are introduced during the growth, thus effectively decreasing the carrier relaxation time(17). For the MBE (111)B CdTe grown on (100) $\mathrm{Si}$, it is suspected that microtwins, dislocations originated from the lattice mismatch with (100) $\mathrm{Si}$, and other point defects, such as $\mathrm{Te}$ interstitial or $\mathrm{Cd}$ vacancies, are believed to be present. These defects seem to play an important role in decreasing the carrier lifetime without significantly decreasing the carrier mobilities.

Linear response to $\mathrm{x}$-ray photons was obtained using white beam from a $\mathrm{Cu}$ rotating anode. The photon flux increases linearly with the electron beam current at an accelerating voltage(18). Therefore the generated carrier density or the resulting response current should increase linearly with the electron beam current. Fig. 3 shows the linearity of the response at various electron beam accelerating voltages. The response current and the response slope increase as the energy increases. However the response currents do not linearly increase with the energy. This is due to 
the decrease of the high energy $x$-ray photon absorption in the CdTe layer. The attenuation coefficient decreases from $1000 \mathrm{~cm}^{-1}$ at $8 \mathrm{KeV}$ to $120 \mathrm{~cm}^{-1}$ at $25 \mathrm{KeV}(19)$. Only photons in low energies are effectively absorbed and higher energy photons pass partially through the thin $\mathrm{CdTe}$ layer without contributing to the photoconductor response currents.

$\mathrm{X}$-ray beam profiles were measured with a photoconductor displaced in and around the beam by small steps. The results for the rotating anode measurements are shown in Fig. 4. The beam sizes were changed using $x$ and $y$ slits placed approximately $15 \mathrm{~cm}$ away from the rotating anode and the device was located at $20 \mathrm{~cm}$ away from the slits. With the slit size of $1.5 \mathrm{~mm}$, the beam profile is a square shape with FWHM of $1.2 \mathrm{~mm}$. Because of the finite size of the $x$-ray beam source, a $600 \mu \mathrm{m}$ - odge-gradient region is observed. The top of the profile is substantially flat, indicating the direct exposure to the rotating anode $x$-ray beam. For a $600 \mu \mathrm{m}$ slit size, FWHM of the profile decreases to $900 \mu \mathrm{m}$ with the same edge-gradient region, but with a slightly lower maximum response. In the measurement configuration, the maximum response of the $x$-ray beam profile decreases with slit sizes less than $1 \mathrm{~mm}$. The decrease of the maximum response is due more to the decrease of the $x$-ray photon flux passing through the smaller slit opening than the finite size source, which is believed to be $1 \mathrm{~mm}$. However, for a slit size larger than $1 \mathrm{~mm}$, the maximum response current remains constant and is independent of the beam size. This observation indicates that the crosstalk in the array devices is negligible. The spatial resolution was measured using synchrotron radiation. In contrast to the rotating anode $\mathrm{x}$-rays, the synchrotron beam has a significantly smaller divergence (Beamline X18B at the NSLS/BNL). In general, significant scattering of $x$-ray photons occurs in the lateral directions for both thick films and screen systems and this often limits spatial resolution $(20)$. On the other hand, thin film detectors, such as the MBE CdTe photoconductor, should provide the resolution as small as the detector size. Fig. 5 shows the spatial response curve with $75 \mu \mathrm{m}$ FWHM using a $50 \mu \mathrm{m}$ synchrotron beam size.

Fig. 6 shows the response energy dependence of an MBE CdTe photoconductor. The monochromator was tuned to energies from 12 to $15 \mathrm{keV}$. The flux was monitored by a $20 \mathrm{~cm}$ long ionization chamber placed before the CdTe photoconductor. Since the generated carrier density in the CdTe is directly related to the $\mathrm{x}$-ray photon energy under the same flux condition, the response increases with photon energy. A linear response is observed in the measured energy range. This observation illustrates that most of the photons in this energy range contribute to the response current of the MBE CdTe photoconductor.

In conclusion, we have shown that MBE CdTe photoconductor linear arrays can be used as fast $\mathrm{x}$-ray detectors. The MBE grown CdTe layers are pure and of enough high quality to provide high resistivities, greater than $10^{8} \Omega-\mathrm{cm}$. The dark currents of the array devices are limited to the $1 \mathrm{nA}$ at $5 \times 10^{4} \mathrm{~V} / \mathrm{cm}$ electric field with an excellent uniformity. In spite of its relative small 
thickness, the photoconductor exhibited the expected performances, such as linear response to $x-$ ray photon flux and energy. A photoconductor was used for profiling of the $x$-ray beams. The photoconductor showed an excellent spatial resolution of $75 \mu \mathrm{m}$ FWHM from a $50 \mu \mathrm{m}$ wide synchrotron beam. Furthermore the same device showed a temporal response as fast as $20 \mathrm{psec}$ risetime. These results illustrate that the $\mathrm{MBE} C \mathrm{CdTe}$ photoconductor is a promising next generation detector for synchrotron radiation applications.

\section{Acknowledgements}

We would like to thank Y. P. Chen for helping with the growth of MBE CdTe layers. This work was supported by the U.S. Department of Energy, BES-Materials Science under contract No. W31-109-ENG-38. 


\section{References}

1. L. Scharager, P. Siffert, A. Holtzer and P. Schiefer, IEEE Trans. Nucl. Sci. NS-27(1), P276 (1989)

2. S. Mergui, M. Hage-Ali, J. M. Koebel and P. Siffert, Nucl. Instr. and Meth. A322, p381 (1992)

3. F. Glasser, G. Thomas, M. Cuzin and L. Verger, Nucl. Inst. Meth. A322 p619 (1992)

4. H. Tsutsui, t. Ohtsuchi, K. Ohmori, and S. Baba, IEEE Trans. Nucl. Sci. vol.40, no.1, p40ä (1993)

5. G. Entine, M. R. Squillante, R. Hahn, L. J. Cirignano, W. McGann, and P. J. Biggs, IEEE Trans. Nucl. Sci. vol.39, no.5, p1480 (1992)

6. Y. Iwase, M. Funaki, A. Onozuka, and M. Ohmori, Nucl. Instr. and Meth. A322, p628 (1992)

7. M. Cuzin, C. Pierrat and E. Rossa, Nucl. Instr. and Meth. A283, p310 (1989)

8. M. C. Nuss, D. W. Kisker, P. R. Smith, and T. E. Harvey, Appl. Phys. Lett. 54(1), p57 (1989)

9. C. Bovet and E. Rossa, Rroc. Particle Accelerator conf., Tsukuba, Japan, p371 (1991)

10. MBE CdTe Photocondutor Position Sensitive Detector for Synchrotron - S. S. Yoo, B. Rodricks, J. P. Faurie, and P. M. Montano - APS Workshop on Detectors for Third -Generation Sysnchrotron Sources, Argonne National Laboratory, IL, Feb 14-15 (1994)

11. Detector Development at the Advanced Photon Source - B. Rodricks; S. S. Yoo, P. Montano, J. P. Faurie - International Workshop on Area Detectors, Harima Science Garden City, Japanä (November, 24, 1993)

12. Ultrafast Photoconductor CdTe Detectors for Synchrotron X-Ray Studies - S. S. Yoo, K.ä Wang, P. A. Montano, J. P. Faurie, Q. Huang, B. Rodricks - Third London Conference on Position-Sensitive Detectors, London, England (September, 28, 1993)

13. Structure of CdTe (111)B Grown by MBE on Misoriented Si (100), Y. P. Chen, S. Sivananthan, and J. P. Faurie, Journal of Electronic Materials, Vol.22, No. 8, p951 (1993)

14. Molecular-beam epitaxy of CdTe on large area Si(100), R. Sporken, M. D. Lange, J. P.ä Faurie, J. Vac. Sci. Technol. B9(3), p1651 (1991)

15. A. M. Jonson, D. W. Kisker, W. M. Simpson, and R. D. Feldman, Picosecond Electronics and Optoelectronics, p 188, Springer-Verlag, edited by G. A. Mourou, d. M. Bloom, and C.-H. Lee (1985)

16. S. Gupta, J. Pamulapati, J. Chwalek, P. K. Bhattacharya, and G. Mourou, Ultrafast Phenomena VII, p297, edited by C. B. Harris, E. P. Ippen, G.A. Mourou, and A. H. Zewailä (1990)

17. M. Kaminska, E. R. Weber, Z. Liliental-Weber, R. Leon, Z. U. Rek, J. Vac. Sci. Technol. B7, p710 (1989)

18. B. D. Cullity, Elements of X-ray Diffraction, chap. 1, 3rd ed. Addison-Wesley Publishing Co. (1967)

19.K. Zanio, Semiconductors and Semimetals, Vol. 13, p164, Academic Press Inc. (1978)

20. B. H. Haseqawa, The Physics of Medical X-ray Imaging, 2nd ed., Medical Physics Publishing Co., p127 (1991) 
Figure Caption

1. Current-voltage characteristics of MBE CdTe photoconductors under dark and illumination conditions. The photogeneration was made by a $60 \mathrm{~W}$ incandescent light bulb placed $40 \mathrm{~cm}$ away from the array.

2. Temporal response of a representative MBE CdTe photoconductor sample. It is noted that the risetime and response FWHM are $20.8 \mathrm{psec}$ and $37.6 \mathrm{psec}$, respectively.

3. The response to white beam $x$ rays is shown at various energies. It is observed that the photoconductor response increases with $\mathrm{x}$-ray energy.

4. Rotating anode $x$-ray beams were profiled by displacing an MBE CdTe photoconductor every $100 \mu \mathrm{m}$ steps in and around the beam. The photoconductor gap size is $20 \mu \mathrm{m}$ and $5 \mathrm{~V}$ bias was applied. The $x$-ray white beam was produced using $50 \mathrm{~mA}$ current and $20 \mathrm{KV}$ accelerating voltage. The slit sizes are a) $1.5 \times 1.5 \mathrm{~mm}$ and b) $0.6 \times 0.6 \mathrm{~mm}$. Because of the finite $x$-ray source size, a $0.6 \mathrm{~mm}$ edge-gradient region is observed and the maximum response is lower for a smaller slit size.

5. Spatial resolution of the MBE CdTe photoconductor measured using a $50 \mu \mathrm{m}$ synchrotron beam size at an energy of $8 \mathrm{keV}$. A $75 \mu \mathrm{m}$ FWHM was obtained from a $20 \times 50 \mu \mathrm{m}$ area photoconductor.

6. Energy dependence response of the $\mathrm{MBE} \cdot \mathrm{CdTe}$ photoconductor measured using a monochromatic beam with energies between 12 and $15 \mathrm{KeV}$ at beamline $\mathrm{X}-18 \mathrm{~B}$ (NSLS). 


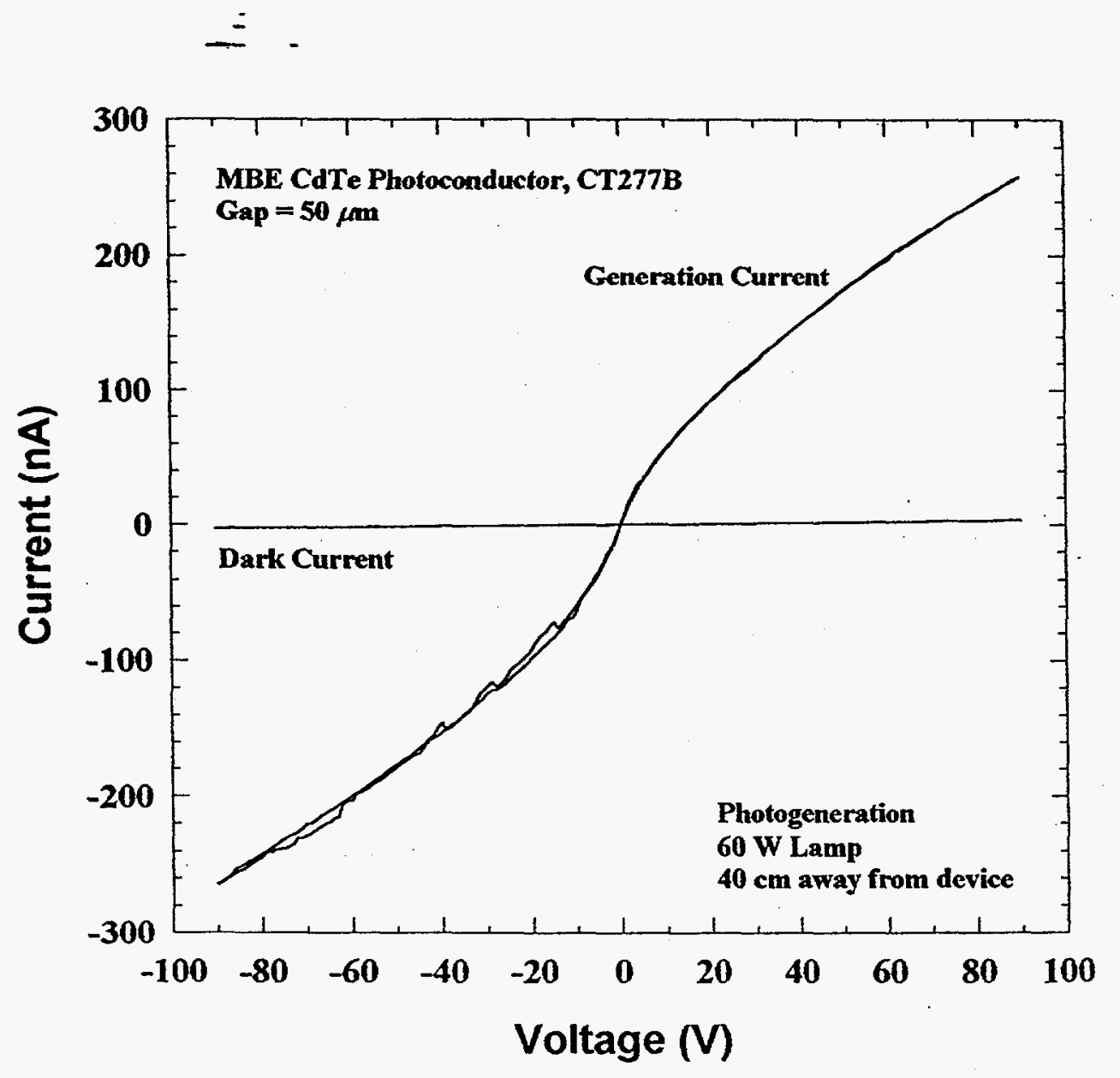




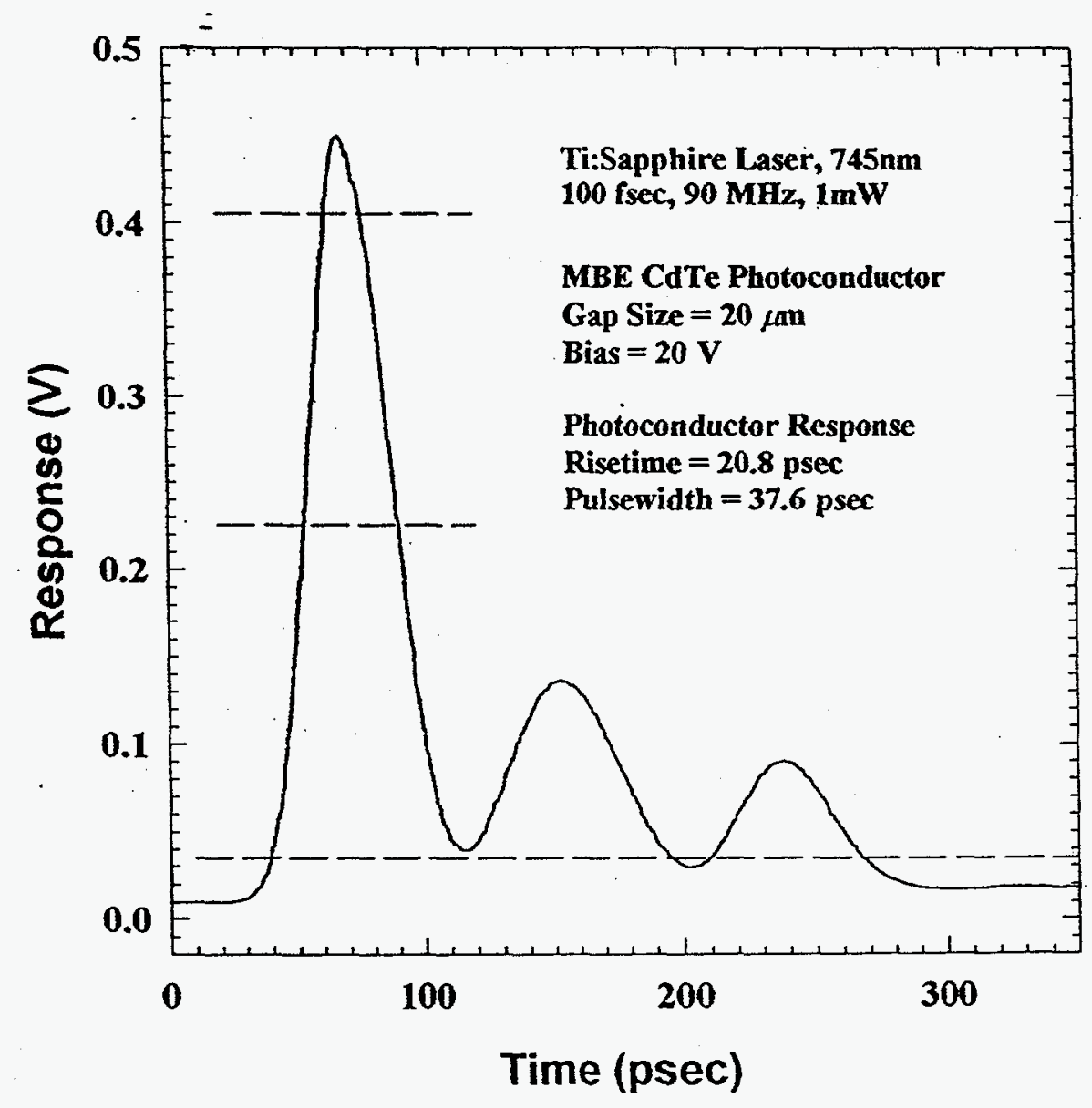




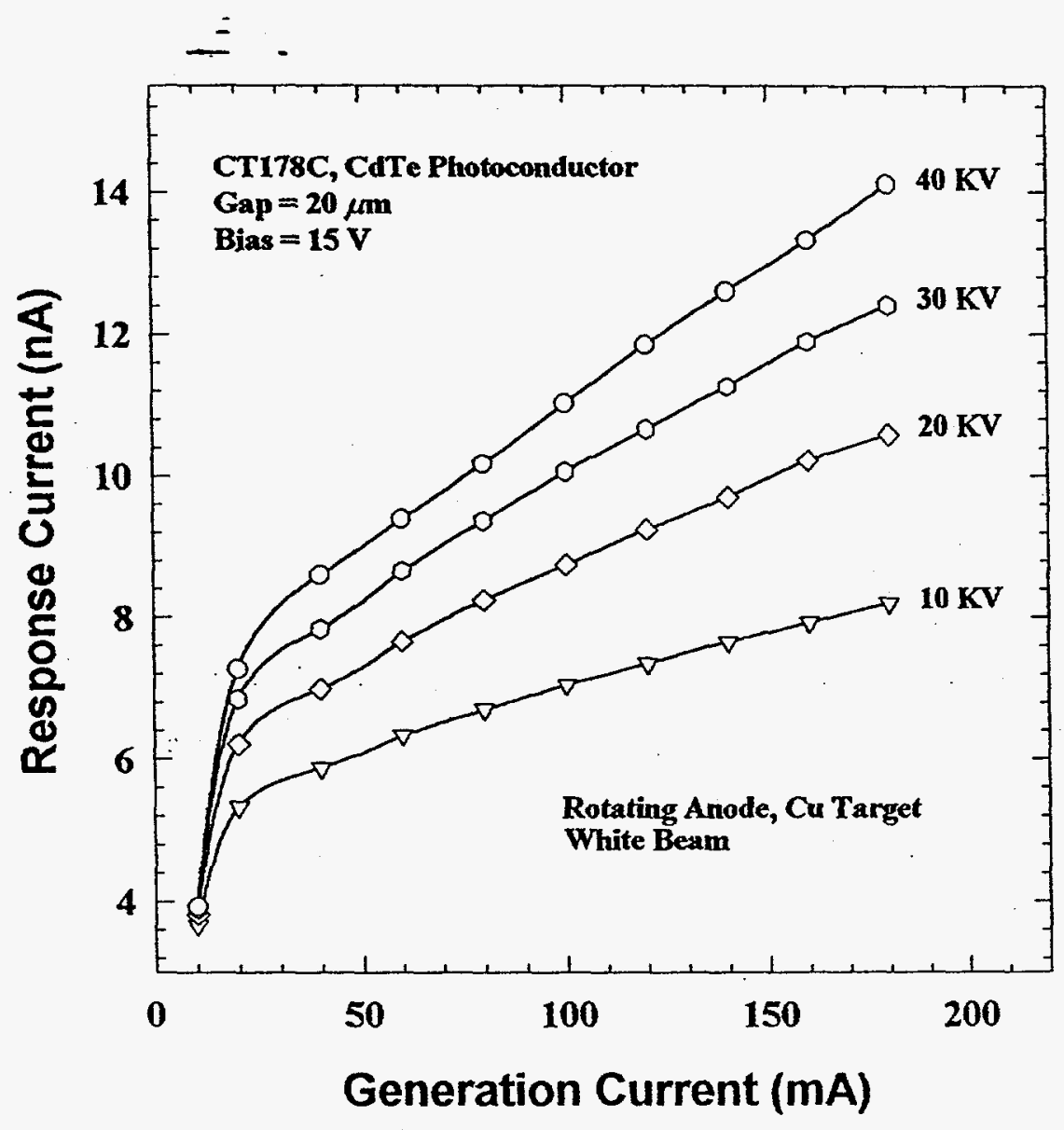




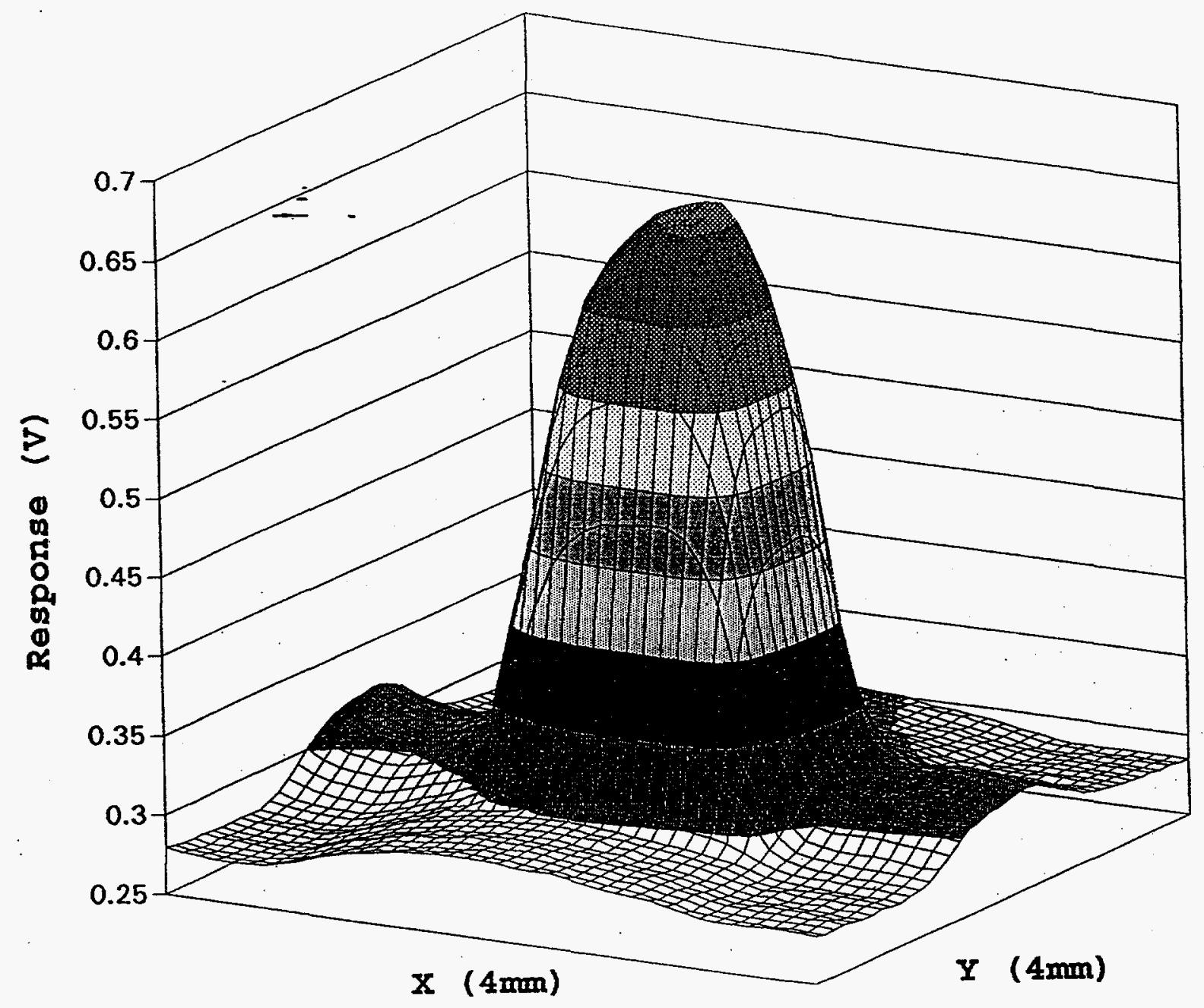




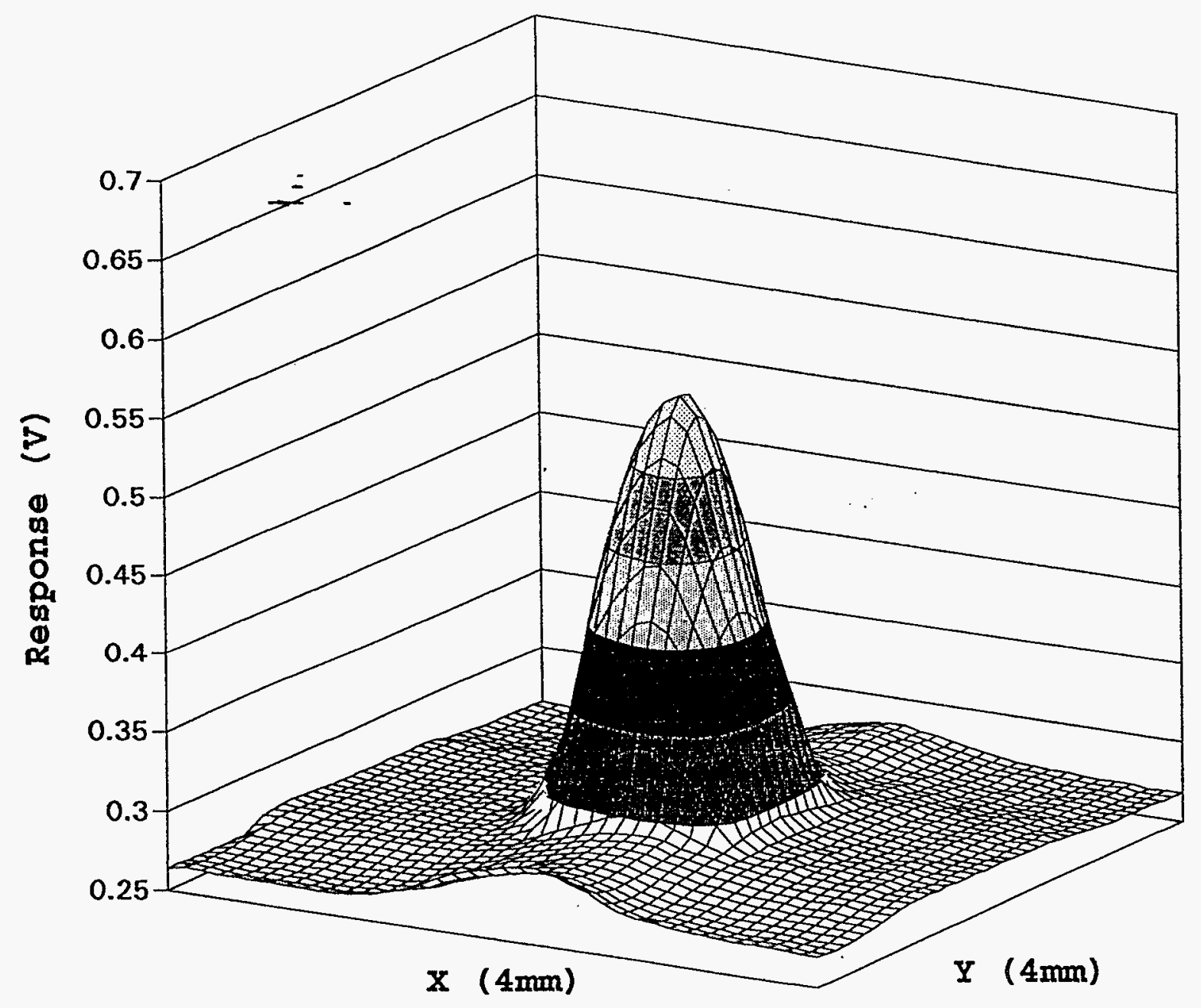




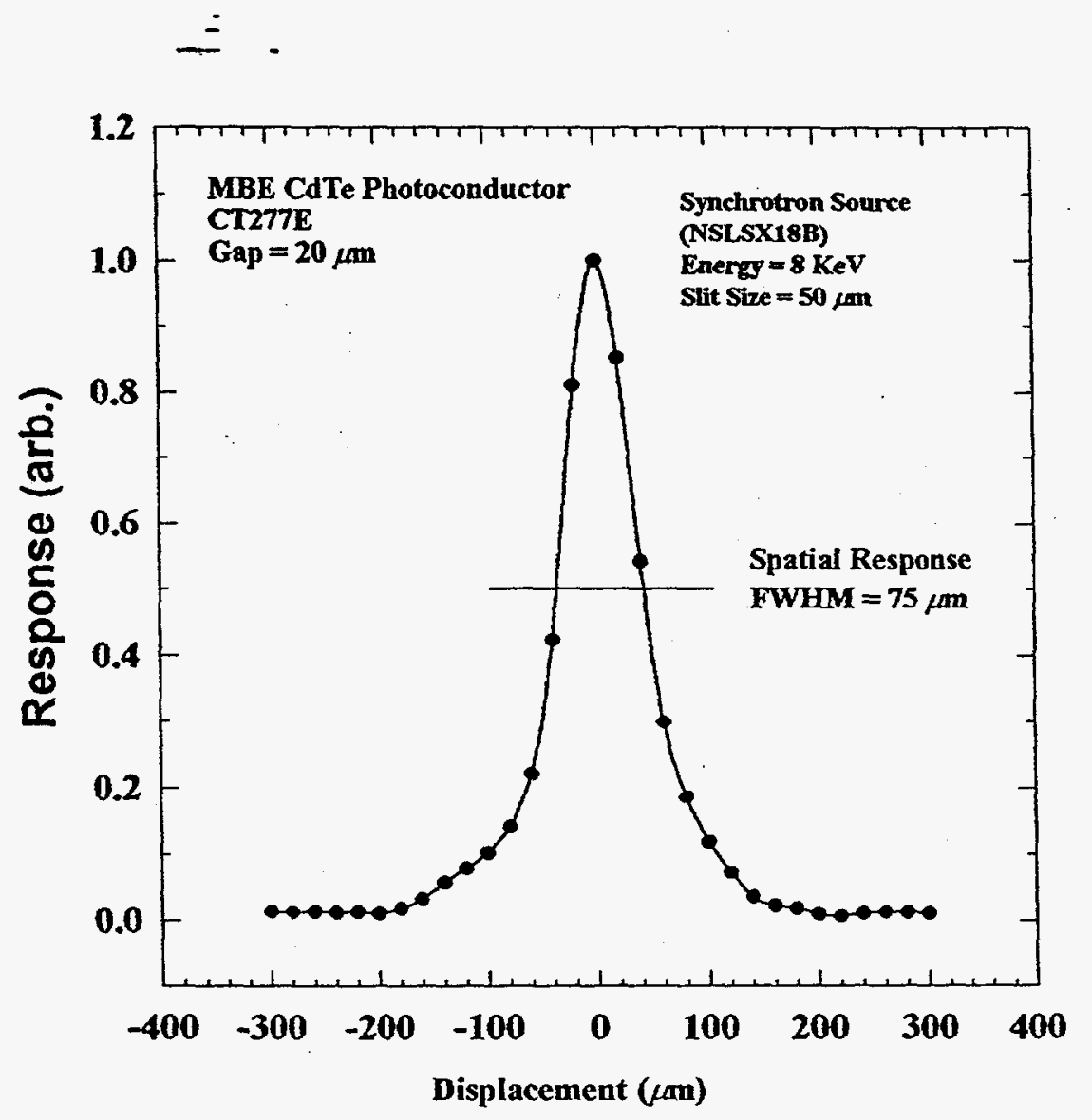




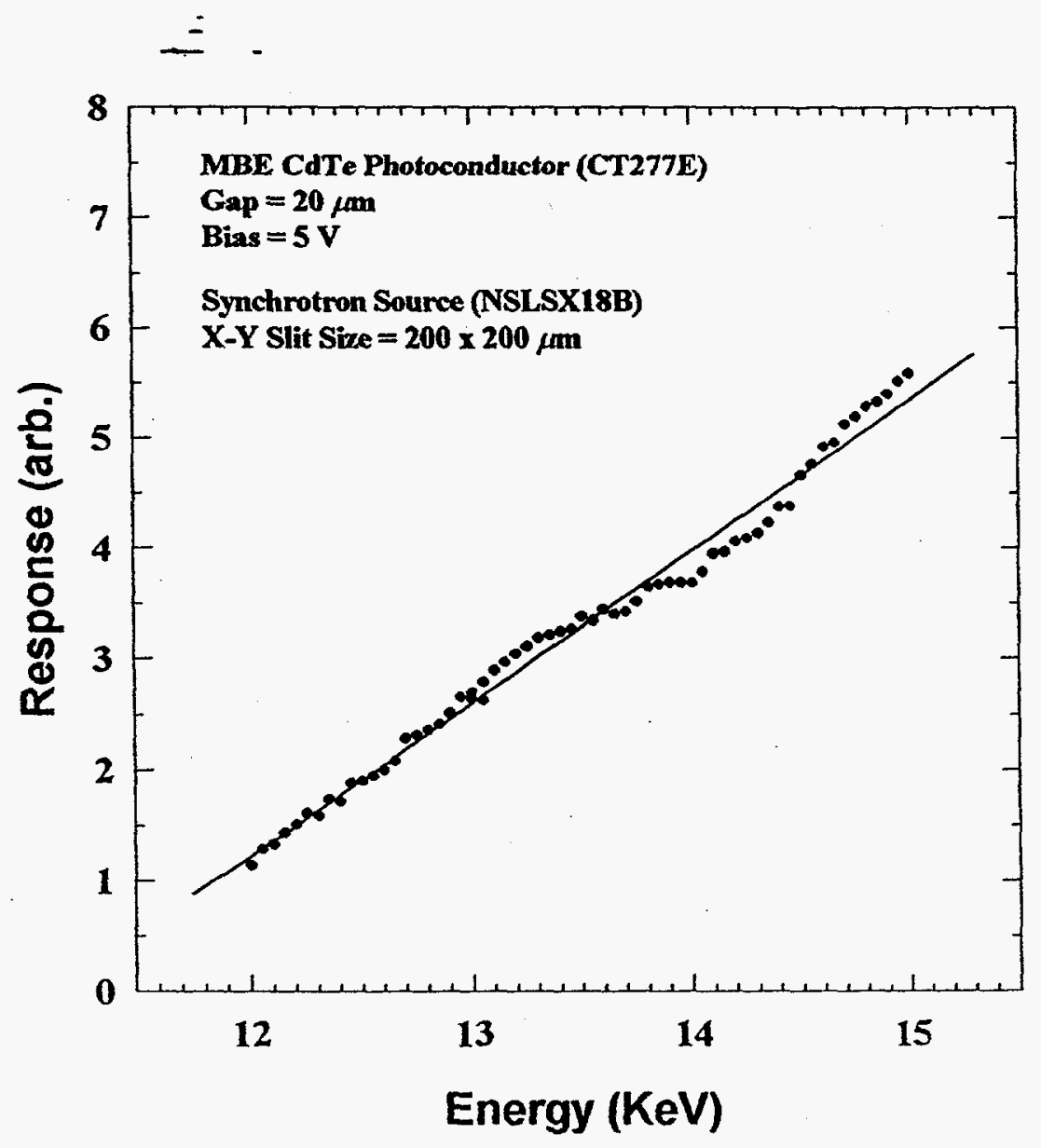

